\title{
Motor and cognitive changes in normal aging
}

\author{
Ahmed A. Moustafa * \\ Department of Veterans Affairs, New Jersey Health Care System, School of Social Sciences and Psychology, Marcs Institute for Brain and Behaviour, University of \\ Western Sydney, Sydney, NSW, Australia \\ *Correspondence: a.moustafa@uws.edu.au
}

Edited by:

Manuel Menéndez-González, Hospital Álvarez-Buylla, Spain

Reviewed by:

Vinay V. Parikh, Temple University, USA

Keywords: aging, motor processes, cognitive processes, dopamine, acetylcholine, basal ganglia, hippocampus, prefrontal cortex

\section{A commentary on}

Effects of aging and involuntary capture of attention on event-related potentials associated with the processing of and the response to a target stimulus

by Cid-Fernandez, S., Lindin, M., and Diaz, F. (2014). Front. Hum. Neurosci. 8:745. doi: 10.3389/fnhum.2014.00745

In a recent study, Cid-Fernandez et al. (2014) tested attentional performance in 3 age groups: young (21-29 years old), middle-aged (51-64 years old), and older adults (65-84 years old). The task used in this study involved presenting both visual and auditory cues to the participants, and they were required to pay attention to the visual cues while ignoring the auditory cues (for task details, see Escera et al., 1998). Cid-Fernandez et al. (2014) found that there was an increase in distractibility and changes in motor selection in the middle-aged and older groups, compared to the young group. These findings were revealed using electroencephalography analyses which related different cognitive and motor processes to different event-related potential components. Impairment in sensory filtering (e.g., longer time to characterize stimuli in working memory), as revealed by differences in the $\mathrm{N} 2 \mathrm{~b}$ component among the groups are presumed to explain the deficits in motor processes (i.e., selection of motor responses). It is thus suggested that these cognitive working memory changes in aging lead to slowing down of motor response selection.

Other prior studies have investigated changes in motor changes in aging (Light, 1990). In one study, it was reported that abnormalities in motor processing are not related to cognitive processing (Kolev et al., 2006). For example, Falkenstein et al. (2006) also reported abnormalities in motor selection processes in healthy aging. However, unlike the Cid-Fernandez et al. (2014) study did not find a different in early stimulus processing. Further, Falkenstein et al. (2006) have only tested younger and older adults. The differences in findings could be related to different age groups in both studies.

What is important about this study is Cid-Fernandez and colleagues (a) have tested both motor and cognitive processes in (b) three age groups. Most existing studies on aging often compare younger (aged 18-30 or 50 years old) with older (aged 60 or 65 years and over) adults (Scott, 1994; Braver and Barch, 2002; Cabeza et al., 2002; Fera et al., 2005; Weiler et al., 2008; Willemssen et al., 2011; Brehmer et al., 2012; Trewartha et al., 2014), and thus do not reveal the subtle motor and cognitive changes that may occur during the aging process, for example at $40 \mathrm{~s}$ or 50s years old. Cid-Fernandez et al. (2014) found that attentional and motor changes can occur from 50 years onwards. Since Cid-Fernandez and colleagues did not recruit participants in their 40s, it is not known whether such cognitive and motor changes can occur at a younger age than reported by the authors. Similarly, studies that recruit only younger and older adults may not reveal the exact age (or age group) at which behavioral and neural changes occur.

Importantly, there are studies that test behavioral performance in more age groups than those recruited in the CidFernandez et al. (2014) study (see for example studies by Davis et al., 2003, 2013; Krishna et al., 2012; Stark et al., 2013). One such study (Davis et al., 2003) recruited 4 groups: Group 1 (30-44 years old), Group 2 (45-59 years old), Group 3 (60-74 years old), Group 4 (75-90 years old). Using the Rey Auditory Verbal Learning Test (RAVLT, which measures memory acquisition, recall, and recognition), Davis et al. (2003) found that memory acquisition was lower in the 60-74 and 75-90 age groups, compared to the other groups. They also found that forgetting after one-day delay was more common in some, but not all, participants in the 75-90 years old group, in comparison to the other age groups. These findings suggest that impairment in cognitive performance occur at different times during the aging process, depending on the cognitive process being investigated as well as age group.

Other studies have recruited participants across various age groups and correlated behavioral performance with age (Davis et al., 2013; Stark et al., 2013). For example, Stark and colleagues reported impaired performance in hippocampusbased tasks in some aging populations (Stark et al., 2013; Bennett et al., 2014). One recent study by Davis and colleagues have recruited participants from age 5 to age 90 (Davis et al., 2013), which is probably among the most inclusive studies of age groups. Davis and colleagues found that verbal learning impairments were common among children and older adults in comparison to younger and middle-aged adults. The benefit of having such a wide range of age groups is to reveal at which age acquisition (in early ages) as well as decline (in older age) of motor and cognitive processes may occur. 
Cid-Fernandez et al. (2014) suggest that their behavioral and physiological findings of impaired attentional performance can be related to changes in the prefrontal cortex during aging. This is supported by an extensive body of research showing impaired prefrontal function during the aging process (West, 1996; Braver and Barch, 2002; Solbakk et al., 2008; Wang et al., 2011; Johnson et al., 2013). In addition to the prefrontal cortex, healthy aging also affects the basal ganglia and hippocampus structures as well as neurotransmitters projecting to these brain regions, including dopamine and acetylcholine (Kaasinen et al., 2000; Inoue et al., 2001; Small et al., 2011). However, it is argued that brain changes (as well as corresponding behavioral decline) do possibly occur at different degrees and at different times during the aging process (Krishna et al., 2012). In one recent study, we found that older adults (75 and above) show more impairment in hippocampalbased tasks compared to less older adults (60-70 years old), but basal ganglia-based learning was impaired in the older and less older groups (Krishna et al., 2012; also see Moustafa et al., 2012). Thus, future work should explain how alterations to certain brain regions and neurotransmitters correspond to specific motor and cognitive changes in different age groups.

The Cid-Fernandez et al. (2014) findings have implications for the understanding of motor and cognitive problems associated with age-related neurodegenerative disorders, including Parkinson's and Alzheimer's diseases. Prior studies have also reported deficits in the selection of motor responses, yet it is not known whether these deficits are due to motor and/or cognitive abnormalities in these in different agerelated neurodegenerative disorders (Hocherman et al., 2004; van Deursen et al., 2009).

\section{REFERENCES}

Bennett, I. J., Huffman, D. J., and Stark, C. E. (2014). Limbic tract integrity contributes to pattern separation performance across the lifespan. Cereb. Cortex. doi: 10.1093/cercor/bhu093

Braver, T. S., and Barch, D. M. (2002). A theory of cognitive control, aging cognition, and neuromodulation. Neurosci. Biobehav. Rev. 26, 809-817. doi: 10.1016/S0149-7634(02) $00067-2$
Brehmer, Y., Westerberg, H., and Backman, L. (2012). Working-memory training in younger and older adults: training gains, transfer, and maintenance. Front. Hum. Neurosci. 6:63. doi: 10.3389/fnhum.2012.00063

Cabeza, R., Anderson, N. D., Locantore, J. K., and McIntosh, A. R. (2002). Aging gracefully: compensatory brain activity in high-performing older adults. Neuroimage 17, 1394-1402. doi: 10.1006/nimg.2002.1280

Cid-Fernandez, S., Lindin, M., and Diaz, F. (2014). Effects of aging and involuntary capture of attention on event-related potentials associated with the processing of and the response to a target stimulus. Front. Hum. Neurosci. 8:745. doi: 10.3389/fnhum.2014.00745

Davis, H. P., Klebe, K. J., Guinther, P. M., Schroder, K. B., Cornwell, R. E., and James, L. E. (2013). Subjective organization, verbal learning, and forgetting across the life span: from 5 to 89. Exp. Aging Res. 39, 1-26. doi: 10.1080/0361073X.2013. 741956

Davis, H. P., Small, S. A., Stern, Y., Mayeux, R., Feldstein, S. N., and Keller, F. R. (2003). Acquisition, recall, and forgetting of verbal information in long-term memory by young, middle-aged, and elderly individuals. Cortex 39, 1063-1091. doi: 10.1016/S0010-9452(08) 70878-5

Escera, C., Alho, K., Winkler, I., and Naatanen, R. (1998). Neural mechanisms of involuntary attention to acoustic novelty and change. J. Cogn. Neurosci. 10, 590-604. doi: 10.1162/089892998562997

Falkenstein, M., Yordanova, J., and Kolev, V. (2006) Effects of aging on slowing of motor-response generation. Int. J. Psychophysiol. 59, 22-29. doi: 10.1016/j.ijpsycho.2005.08.004

Fera, F., Weickert, T. W., Goldberg, T. E., Tessitore, A., Hariri, A., Das, S., et al. (2005). Neural mechanisms underlying probabilistic category learning in normal aging. J. Neurosci. 25, 11340-11348. doi: 10.1523/JNEUROSCI.273605.2005

Hocherman, S., Moont, R., and Schwartz, M. (2004). Response selection and execution in patients with Parkinson's disease. Brain Res. Cogn. Brain Res. 19, 40-51. doi: 10.1016/j.cogbrainres.2003. 11.001

Inoue, M., Suhara, T., Sudo, Y., Okubo, Y., Yasuno, F., Kishimoto, T., et al. (2001). Age-related reduction of extrastriatal dopamine $\mathrm{D} 2$ receptor measured by PET. Life Sci. 69, 1079-1084. doi: 10.1016/S00243205(01)01205-X

Johnson, R. Jr., Nessler, D., and Friedman, D. (2013). Temporally specific divided attention tasks in young adults reveal the temporal dynamics of episodic encoding failures in elderly adults. Psychol. Aging 28, 443-456. doi: 10.1037/ a0030967

Kaasinen, V., Nagren, K., Hietala, J., Oikonen, V., Vilkman, H., Farde, L., et al. (2000). Extrastriatal dopamine D2 and D3 receptors in early and advanced Parkinson's disease. Neurology 54, 1482-1487. doi: 10.1212/WNL. 54.7.1482

Kolev, V., Falkenstein, M., and Yordanova, J. (2006). Motor-response generation as a source of agingrelated behavioural slowing in choice-reaction tasks. Neurobiol. Aging 27, 1719-1730. doi: 10.1016/j.neurobiolaging.2005.09.027

Krishna, R., Moustafa, A. A., Eby, L. A., Skeen, L. C., and Myers, C. E. (2012). Learning and generalization in healthy aging: implication for frontostriatal and hippocampal function. Cogn. Behav. Neurol. 25, 7-15. doi: 10.1097/WNN.0b013e3182 $48 \mathrm{ff} 1 \mathrm{~b}$

Light, K. E. (1990). Information processing for motor performance in aging adults. Phys. Ther. 70, 820-826.

Moustafa, A. A., Hewedi, D. H., Eissa, A. M., Myers, C. E., and Sadek, H. A. (2012). The relationship between associative learning, transfer generalization, and homocysteine levels in mild cognitive impairment. PLoS ONE 7:e46496. doi: 10.1371/journal.pone.0046496

Scott, M. I. (1994). Auditory memory and perception in younger and older adult second language learners. Stud. Second Lang. Acquis. 16, 263-281. doi: 10.1017/S0272263100013085

Small, S. A., Schobel, S. A., Buxton, R. B., Witter, M. P., and Barnes, C. A. (2011). A pathophysiological framework of hippocampal dysfunction in ageing and disease. Nat. Rev. Neurosci. 12, 585-601. doi: 10.1038/nrn3085

Solbakk, A. K., Fuhrmann Alpert, G., Furst, A. J., Hale, L. A., Oga, T., Chetty, S., et al. (2008). Altered prefrontal function with aging: insights into age-associated performance decline. Brain Res. 1232, 30-47. doi: 10.1016/j.brainres.2008. 07.060

Stark, S. M., Yassa, M. A., Lacy, J. W., and Stark, C. E. (2013). A task to assess behavioral pattern separation (BPS) in humans: data from healthy aging and mild cognitive impairment. Neuropsychologia 51, 2442-2449. doi: 10.1016/j.neuropsychologia.2012. 12.014

Trewartha, K. M., Garcia, A., Wolpert, D. M., and Flanagan, J. R. (2014). Fast but fleeting: adaptive motor learning processes associated with aging and cognitive decline. J. Neurosci. 34, 13411-13421. doi: 10.1523/JNEUROSCI.148914.2014

van Deursen, J. A., Vuurman, E. F., Smits, L L., Verhey, F. R., and Riedel, W. J. (2009). Response speed, contingent negative variation and P300 in Alzheimer's disease and MCI. Brain Cogn. 69, 592-599. doi: 10.1016/j.bandc.2008. 12.007

Wang, M., Gamo, N. J., Yang, Y., Jin, L. E., Wang, X. J., Laubach, M., et al. (2011). Neuronal basis of age-related working memory decline. Nature 476 , 210-213. doi: 10.1038 /nature 10243

Weiler, J. A., Bellebaum, C., and Daum, I. (2008). Aging affects acquisition and reversal of reward-based associative learning. Learn. Mem. 15, 190-197. doi: 10.1101/lm. 890408

West, R. L. (1996). An application of prefrontal cortex function theory to cognitive aging. Psychol. Bull. 120, 272-292. doi: 10.1037/0033-2909. 120.2.272

Willemssen, R., Falkenstein, M., Schwarz, M., Muller, T., and Beste, C. (2011). Effects of aging, Parkinson's disease, and dopaminergic medication on response selection and control. Neurobiol. Aging 32, 327-335. doi: 10.1016/j.neurobiolaging.2009.02.002 
Conflict of Interest Statement: The author declares that the research was conducted in the absence of any commercial or financial relationships that could be construed as a potential conflict of interest.

Received: 17 October 2014; accepted: 11 November 2014; published online: 25 November 2014
Citation: Moustafa AA (2014) Motor and cognitive changes in normal aging. Front. Aging Neurosci. 6:331. doi: 10.3389/fnagi.2014.00331

This article was submitted to the journal Frontiers in Aging Neuroscience.

Copyright (c) 2014 Moustafa. This is an open-access article distributed under the terms of the Creative
Commons Attribution License (CC BY). The use, distribution or reproduction in other forums is permitted, provided the original author(s) or licensor are credited and that the original publication in this journal is cited, in accordance with accepted academic practice. No use, distribution or reproduction is permitted which does not comply with these terms. 